\title{
PFA-linings for avoidance of dewpoint corrosion in heat-exchangers and ducts of waste-incineration power plants
}

\author{
M. Lotz \\ Quadrant EPP AG, Switzerland
}

\begin{abstract}
The combustion of wastes of diverging qualities leads to the formation of gases with a high content of sulphur, chlorine and fluorine compounds. When the dewpoint of these gases is underrun in heat exchangers, housings and ducts in order to re-cycle more heat out of the combustion gases, this leads to a heavy condensation of hydrochloric, hydrofluoric and sulphuric acid on the involved equipment and in consequence to one of the strongest types of corrosion known, called dewpoint corrosion. The latter even corrodes the most resistant steel grades and thus requires other technical solutions. A lining of the condensing heat-exchangers, their housings and the flue gas ducts with the fully-fluorinated thermoplastic PFA (tetrafluoroethylene-perfluoroalkylvinylether) renders possible a service of the heat exchangers under condensing conditions and consequently increases the total power production efficiency of the wasteincineration plant, even having a positive environmental effect due to a positive influence on the overall energy mix. Although the suitability of this technical principle had already been demonstrated in multiple successful examples in fossil- and waste-fired power plants, constructive and technical details can have an influence on the performance of the lined equipment, such as material properties, welding of the liner, installation and sealing against the unlined parts as well as constructive aspects of the heat exchanger pipes and tubes. This will be discussed in the following.

Keywords: waste incineration, dew point corrosion, PFA, linings, fix points, PTFE.
\end{abstract}




\section{Introduction}

\subsection{Dew point corrosion in power plants}

Combustion of fossil fuels or waste leads to the formation of gases containing sulphur, chlorine and fluorine. The dewpoint of the flue gases typically is reached if the gas temperature drops below approx. $125^{\circ} \mathrm{C}$, which however depends on the exact combustion gas composition (Oil \& Gas Journal [1]). Then, droplets of sulphuric acid, hydrochloric acid and hydrofluoric acid form on the surfaces of the heat exchangers and the surrounding equipment. Accordingly, these heat exchangers are called condensing heat exchangers. The condensation of the acid droplets on the metal surfaces leads to the so called dew point corrosion (Huijbregts and Leferink [2], Lewandowski [3], McKetta [4]). If at all, only high nickel alloys are able to resist the extremely corrosive conditions, whereas regular steels and stainless steels are destroyed (Cox et al. [5], de Weijer and Huijbregts [6], Agarwal and Grossmann [7]).

In order to increase the total efficiency of the power production process, dewpoint temperatures are underrun. For this, condensing heat exchangers are installed in addition to the known air pre-heaters.

The efficiency increase of the total power production process, which can be achieved with condensing heat exchangers depends on the total setup of the power plant, moisture (in case of coal fired plants) and the flue gas composition. The efficiency increase typically is in a range of 0.5 to $1.5 \%$ in Europe. In American and Asian countries the potential is even higher (up to 5\%). In consequence, fossil fuels and emissions can be saved, if condensing heat exchangers are used in fossil-fired power plants and waste incineration plants.

\subsection{PFA}

PFA is a semi-crystalline, fully fluorinated thermoplastic. The strong chemical bond between the carbon backbone of the plastic molecules can hardly be broken by chemical attack of the compounds contained in the flue gas stream, and the fluorine side chains of the carbon backbone shield the latter against chemical attack. In combination, this confers an extreme chemical and temperature resistance to the PFA material.

Unlike sintered fluoropolymers like PTFE and modified PTFE, PFA forms a liquid melt and hence can be extruded into foils and pipes. In contrast, foils from PTFE and modified PTFE are skived from sintered blocks and hence vary in their quality alongside the cooling radius of the sintered drums. Furthermore, PTFE and modified PTFE can have micro-pores in regions of imperfect sintering, which then also lead to a weakening of the protective effect of these materials. Both effects, quality variations due to diverging temperature regimes during the cooling phase of the sintering and micro-pores are not found in PFA due to the technically completely diverging melt-extrusion process.

The ability of PFA to flow in the molten state furthermore renders possible to weld PFA sheets with PFA weld rods, and to achieve weld seam qualities, which 
are close to the strength of the parental, non-welded material (Fig. 1). Such weld seam qualities cannot be reached using sintered fluoropolymers, since the melt of sintered polymers does not flow. Besides its excellent thermoforming-properties, the ability of PFA to form strong weld seams is a crucial prerequisite to yield long life times of the lined equipment.

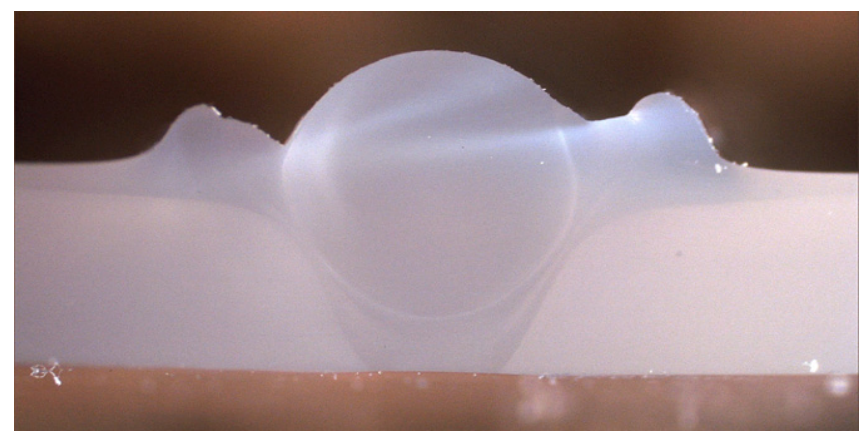

Figure 1: $\quad$ Picture of a typical PFA weld seam (cross-section). The molten material of the plate and the weld rod (round, in the middle) coalesce and hence lead to weld strengths close to the non-welded material.

\section{Condensing heat exchangers and housings}

\subsection{Location of the condensing heat exchangers in the flue gas stream}

Condensing heat exchangers are located after the boiler, air pre-heaters and electrical precipitators (Fig. 2). The condensing heat exchangers are furthermore upstream of the FGD (flue gas desulphurisation). Upstream of the condensing heat exchangers the gas temperatures are high and no flue gas condensation occurs. Therefore, metals are the appropriate material for these regions in the flue gas stream. In the FGD section, the flue gases are less corrosive and the gas temperatures lowered to a point, where often cheaper materials like polypropylene (usable to approx. $100^{\circ} \mathrm{C}$ ) can be used. Hence, the usage of PFA linings and condensing heat exchangers is attributed to a particular part in the flue gas stream, where the corrosion is extremely high and the temperatures still too high to use other plastic materials. Gas/liquid (gas: flue gas stream, liquid: heat transfer media) condensing heat exchangers are hold in a steel frame, lined with PFA natural foil in thickness $1.5 \mathrm{~mm}$ and $2.3 \mathrm{~mm}$; both thicknesses often are mixed depending on the mechanical load of the foil. For example in a system of the company Flucorrex AG, the liquid runs through steel pipes, coated with enamel and an additional PFA tube in order to protect the tubes against the chemically extremely aggressive environment (Fig. 3).

In gas/gas (gas 1: flue gas stream, gas 2: heat transfer media) heat exchangers, the frame also consists of PFA lined steel, but the tubes are made from glass (Fig. 4). 


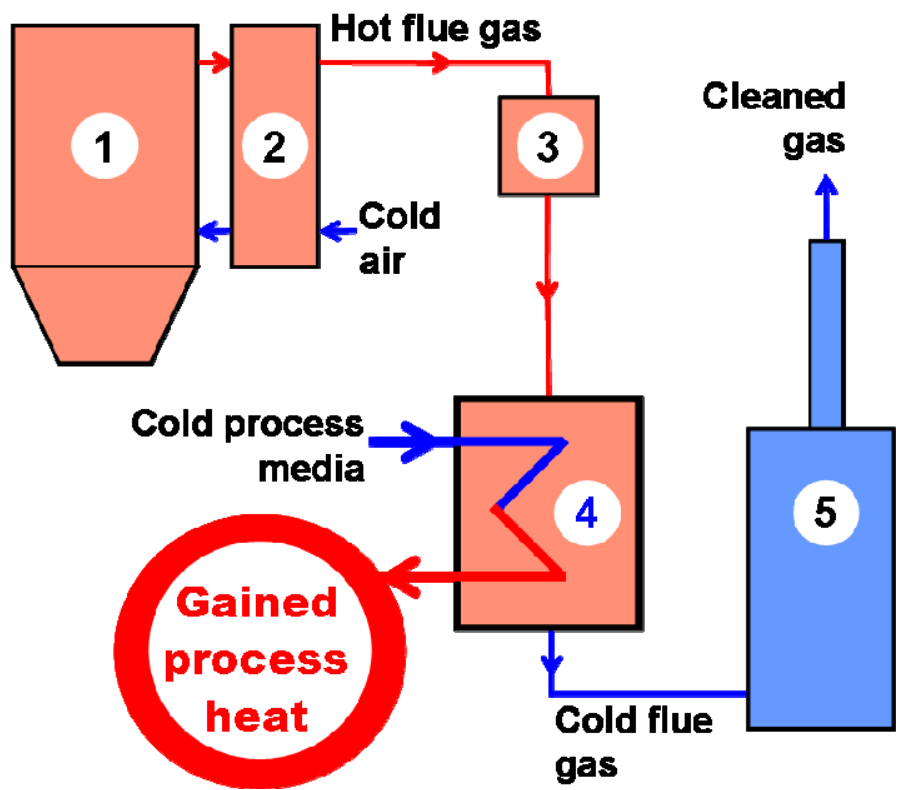

Figure 2: Scheme of flue gas stream. (1) Boiler, (2) air pre-heater, (3) electrostatic precipitator, (4) PFA-lined condensing heat exchanger/flue gas cooler, (5) FGD scrubbers.

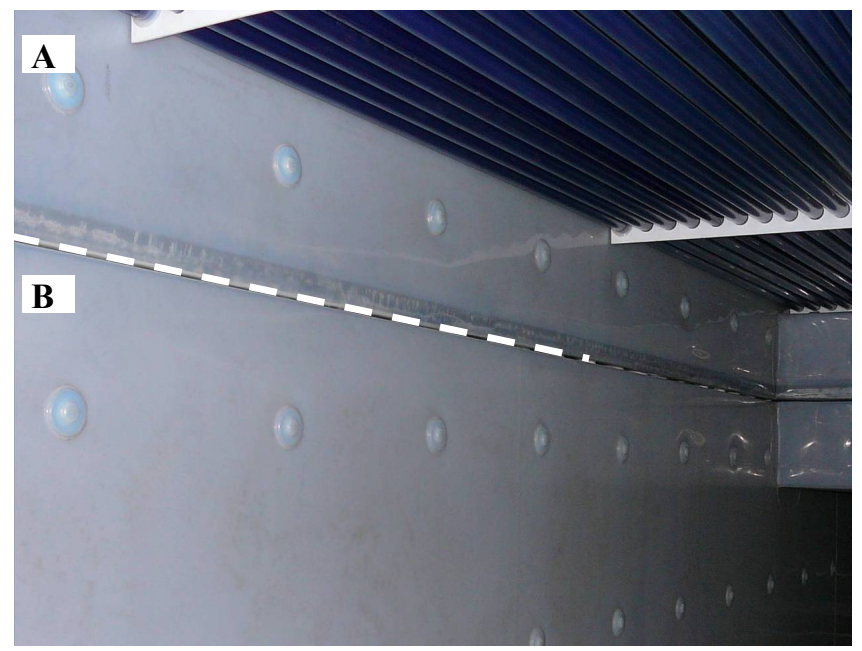

Figure 3: Gas/liquid condensing heat exchanger. The PFA fix point lining resists application temperatures of $260^{\circ} \mathrm{C}$. $(\mathrm{A}=$ above dashed line. $)$ Heat exchanger element. The visible tubes were made of carbon steel, coated with enamel and lined with PFA. (B) PFA-lined inspection room between to exchanger elements. Courtesy Flucorrex AG, CH-Flawil. 


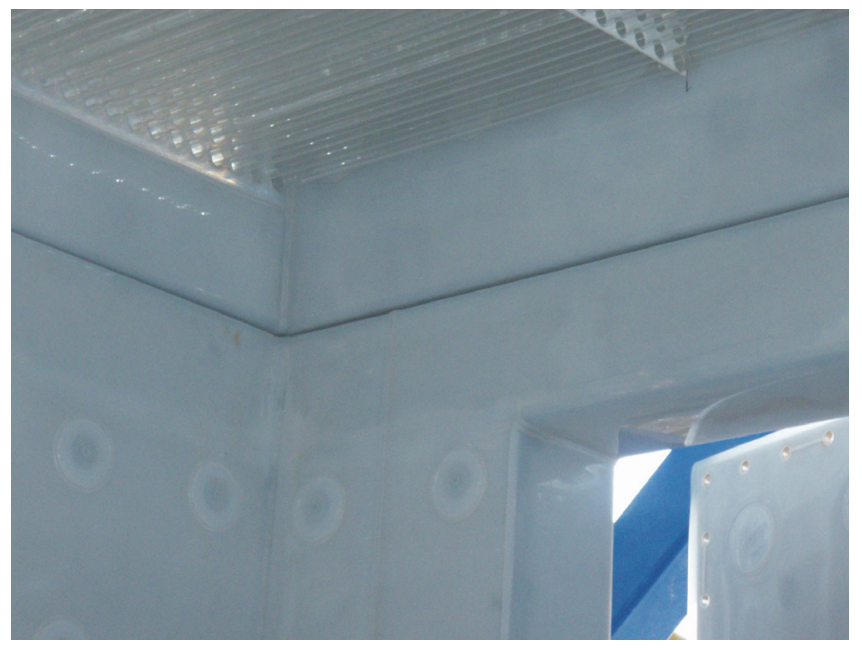

Figure 4: Gas/gas condensing heat exchanger. The gaseous heat transfer media runs through glass pipes. Courtesy Panergetic AG, FLSchaan.

\subsection{Flue gas ducts and housings}

Likewise for the heat exchangers, PFA linings are applied onto the metal surfaces of the ducts and housings in order to protect them against dew point corrosion (Fig. 5). Thereby, the seals in the transition zones towards the following sections of the flue gas ducts are a critical part for the performance of the lining and require a high level of experience of the companies carrying out the lining works (Fig. 6). The duct walls downstream of the PFA lining thereby often are coated with resin containing glass flakes (flake coating), which resists the flue gas conditions following the condensing heat exchangers.

Other critical parts can be for example the floor regions: for cleaning, the condensing heat exchangers are flushed from time to time with water, which afterwards runs along the floor. If the workmanship of the weld seams in the floor region is not sufficient or the weld seam design is not chosen appropriately, this can lead to leakage problems with the cleaning water.

\subsection{Liner installation}

The occurring high temperatures in the flue gas stream have to be considered for the way of liner installation in the piece of equipment. Bonded installations using resins and adhesives as known for PFA linings for liquid media or wet fumes in chemical industry cannot be used, because a bonded connection cannot stand temperatures above $160^{\circ} \mathrm{C}$ (in FRP; material and fabrication dependent) and $120^{\circ} \mathrm{C}$ (in steel; material and fabrication dependent). Therefore, a mechanical fixation without resins or adhesives is chosen for the PFA foils in condensing heat exchangers, flue gas ducts and housings. Then, the full temperature range of 


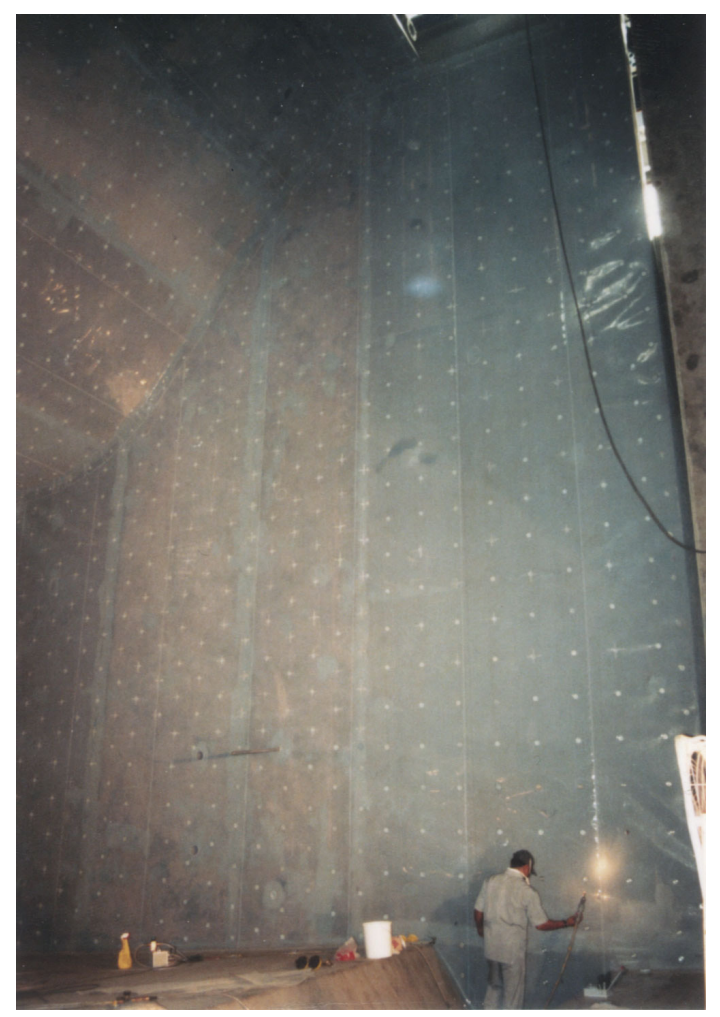

Figure 5: PFA-lined flue gas duct of a waste incineration plant. Courtesy Plasticon Europe, D-Dinslaken.

the PFA material of up to $260^{\circ} \mathrm{C}$ can be used, which is sufficient for the flue gas temperatures in the condensing heat exchanger region.

Two methods of mechanical fixation are used. For the first method, the PFA lining foils are brought into the shape of the equipment piece, which has to be lined, by tailoring, thermo-forming and welding. The fixation of the liner is only done over the flanges, where it is 'clamped' (loose or clamped liner; Fig. 7). An advantage is a relatively quick installation and an easy replacement of the liner, when required. Disadvantages are a limitation to comparatively small work pieces; if high walls have to be lined, the PFA foil has to be supported due to its relatively high weight (approx. $3.4 \mathrm{~kg} / \mathrm{m}^{2}$ for a natural foil of thickness $1.5 \mathrm{~mm}$ ). Furthermore, a loose lining cannot be used, if significant negative pressures have to be expected.

For the second method, PFA linings are applied using an appropriate number of screws, washers and bolts per area for the fixation (fix point linings). Fix point linings are common for the lining of condensing heat exchangers and housings, where large areas have to be lined and changing flue gas pressures can occur. The number of fix points usually is in a range of 8-12 per square meter, but can vary significantly if lower or higher mechanical loads are expected (Fig. 7). 


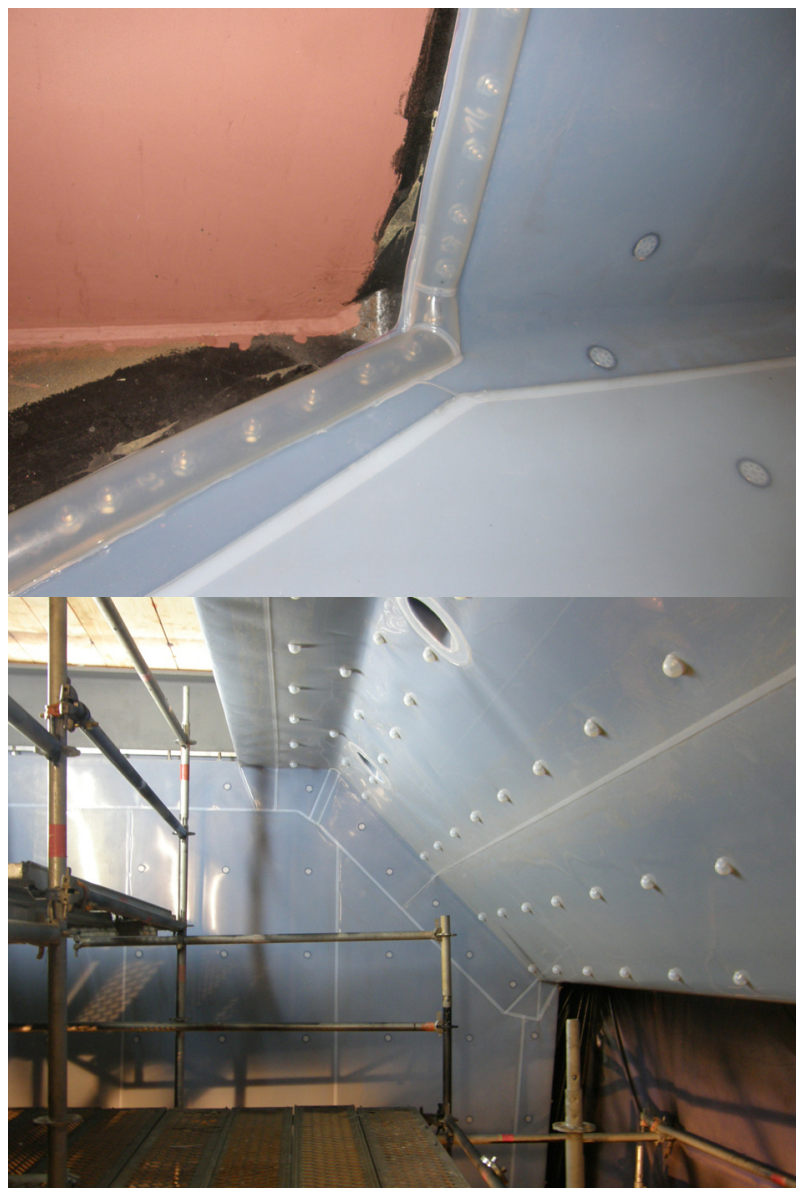

Figure 6: Examples for PFA linings fabricated on a high technical level. Transition zone (upper) and lining of a housing with two diverging fix point application methods (lower). Courtesy Plasticon Europe, D-Dinslaken.

The fix points are covered with welded PFA caps in order to seal the surface completely against the flue gasses. Thereby, either caps made from thermoformed PFA foils or injection-moulded PFA caps can be used (Fig. 8). Injectionmoulded PFA caps have the advantage that they can be produced in the shape of washer and screw, which leads to a relatively flat assembly. In addition, the time-consuming thermo-forming step can be saved. On the other hand, thermoformed PFA caps can be produced from the same PFA foils as used for the lining, which is advantageous for welding (identical melt flow index). 


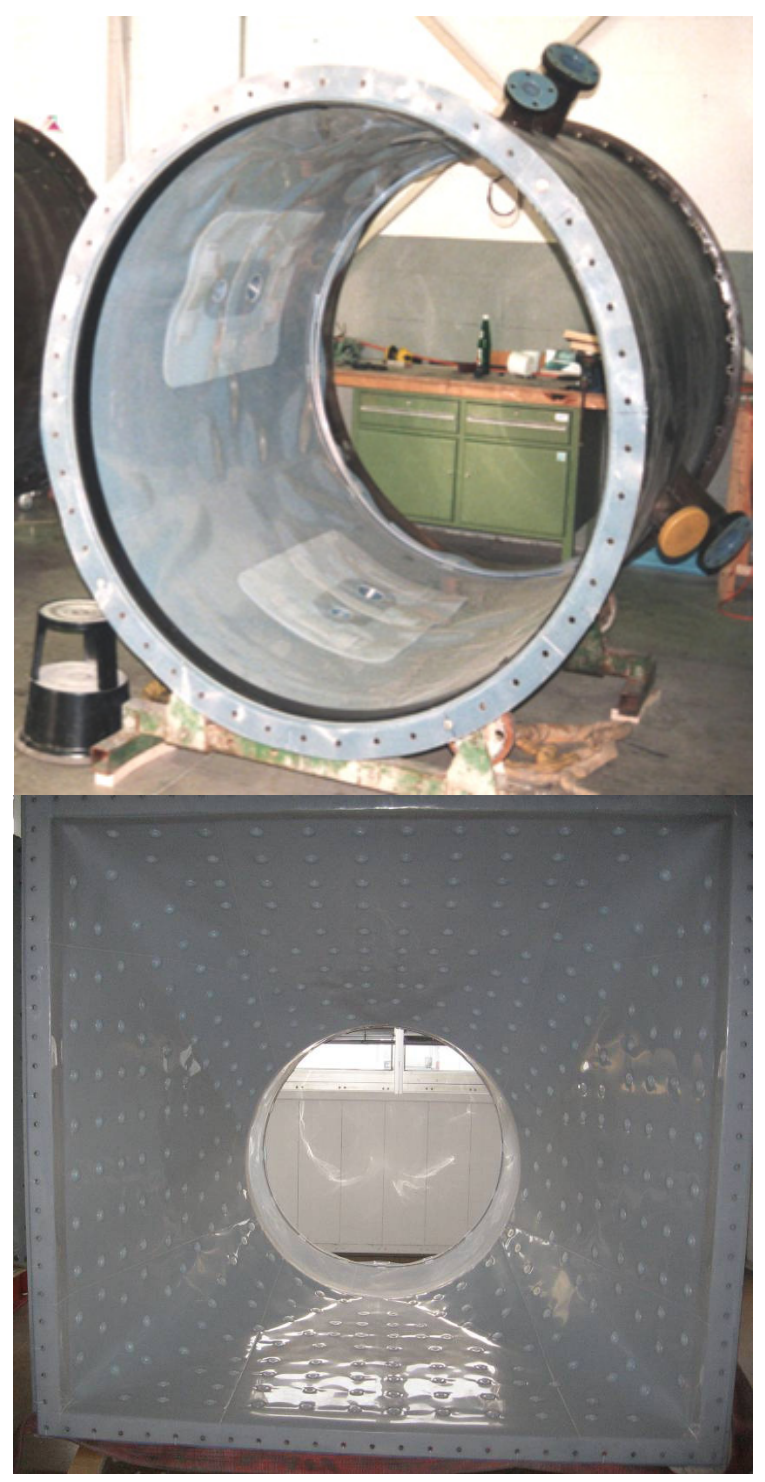

Figure 7: Examples mechanically fixated PFA linings for condensing flue gas applications. Clamped loose lining (upper) and fix point lining of a heat exchanger hood (lower). The hood is exposed to high mechanical loads due to the gas stream velocities. Accordingly, the foil is supported by a comparatively large number of fix points. Courtesy Plasticon Europe, D-Dinslaken (upper) and Flucorrex AG, CH-Flawil (lower). 

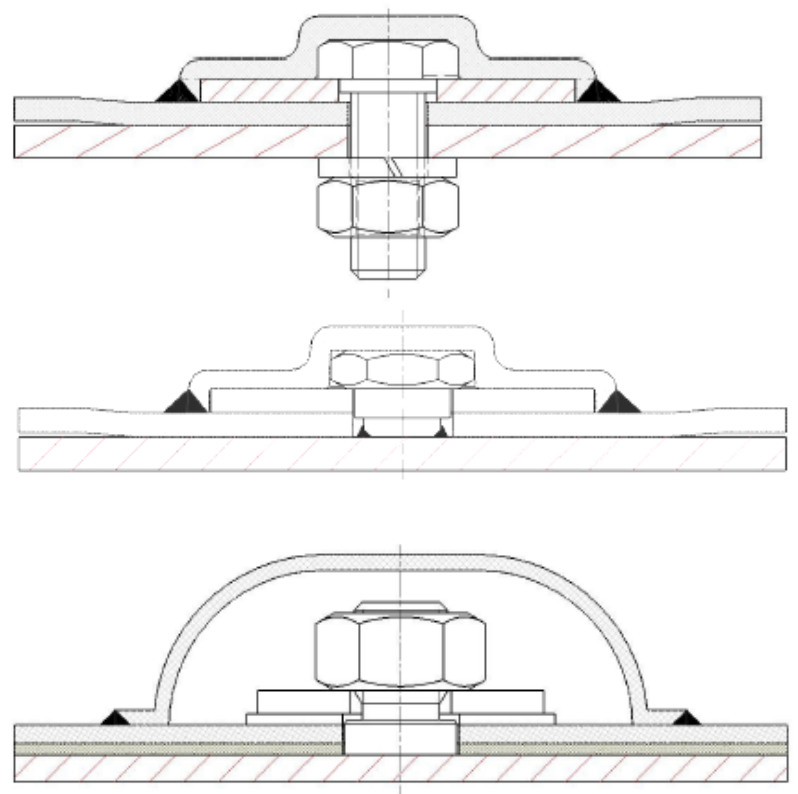

Figure 8: Drawings of typical fix point constructions. Injection-moulded PFA cap and hexagonal screw (upper), injection-moulded PFA cap and welded bolt (middle) as well as thermo-formed PFA cap and hexagonal nut (lower).

The fix points at the same time protect the PFA weld seams against the influences of the thermal expansion of the foil: if the fix points are placed close enough to the weld seams, the influence of the thermal expansion on the weld seams can be kept low.

\subsection{Thermal retraction after heating of PFA foils}

Besides a good quality of the PFA weld rods (typically in thickness $3.5 \mathrm{~mm}$ or $4 \mathrm{~mm}$ ), the retraction after heat behaviour of the used PFA foils (typically delivered in dimensions of $1.5 \mathrm{~mm} \times 1250 \mathrm{~mm} \times 20000 \mathrm{~mm}$ or $2.3 \mathrm{~mm}$ $\mathrm{x} 1250 \mathrm{~mm} \times 10000 \mathrm{~mm}$ ) is important for the liner design and performance.

Retraction after heat in this respect means that the PFA foils shrink to some extend after they had been heated. The shrink thereby is caused by crystallisation events in the material and is a normal behaviour of all semi-crystalline thermoplastic materials. The effect becomes more significant, the closer the application temperatures of the materials come to the melting temperature of the semi-crystalline thermoplastics (Peterson [8]).

Accordingly, the phenomenon usually can be technically neglected in fluoropolymer-lined equipment for wet media as it is used for example in chemical industry, since the application temperatures do not come close to the melting temperatures (for PFA: $290-310^{\circ} \mathrm{C}$ ). 
However, in hot flue gas applications a significant shrink in the foil can occur as the temperatures go up to $260^{\circ} \mathrm{C}$. This on the one hand has to be taken into account when the lined equipment is designed. On the other hand, PFA foils manufactured from the suppliers with a minimum shrink should be chosen to minimise the effect and hence to reduce the risk of heat shrink problems in the lined equipment.

Noteworthy, the retraction after heat values of diverging PFA foil manufacturers can differ. Whereas some suppliers define the values for $200^{\circ} \mathrm{C}$, others provide heat shrink values at $250^{\circ} \mathrm{C}$ temperatures. Since the heat shrink becomes more severe, if the temperatures come close to the melting point of PFA, the heat shrink at $250^{\circ} \mathrm{C}$ in our opinion should be observed, if retraction after heat can be critical.

\section{Conclusions}

Lining with the fully fluorinated polymer PFA is a powerful tool to handle dew point corrosion in fossil-fired and waste incineration plants. The linings can be used to gain more energy from the combustion process and to protect FGD equipment, respectively. The lining system technology, workmanship and quality of the foil however play a key role for the performance of the lined equipment and should be chosen appropriately.

The author likes to thank the companies Plasticon Europe, Flucorrex AG and Panergetic AG for providing the images of the lined equipment.

\section{References}

[1] Oil \& Gas Journal. New correlation predicts dewpoints of acidic combustion gases. 22 February 2010.

[2] W. M. M. Huijbregts, R. G. I. Leferink, Anti Corrosion Methods and Materials Volume 51, No 3, (2004), 173-188.

[3] David A. Lewandowski. Design of Thermal Oxidation Systems for Volatile Organic Compounds, 1st Edition (2000). CRC Press. ISBN 1-56670-410-3.

[4] John J. McKetta. Encyclopedia of Chemical Processing and Design, Volume 61, 1st Edition (1997). CRC Press. ISBN 0-8247-2612-X.

[5] W. Cox, W. Huijbregts, R. Leferink, Components Susceptible to Dew-Point Corrosion. ASM Handbook Volume 13C, Corrosion: Environments and Industries (2006). ASM International. 491-496.

[6] T. de Weijer, W. Huijbregts. Severe corrosion in a waste incinerator plant due to flue gas and steam leakage. Anti-corrosion methods and Materials Volume 50 (2003). 334-340.

[7] D. C. Agarwal and G.K. Grossmann, Case Histories on the Use of Nickel Alloys in Municipal and Hazardous Waste Fueled Facilities. CORROSION. (2001), March 11 - 16, 2001, Houston, Tx. Copyright NACE International.

[8] J. M. Peterson. An energy-driven mechanism for retractive forces in semicrystalline polymers. Polymer letters Volume 7 (1969). 231-236. 